\title{
Scrutinizing the drug resistance mechanism of multi- and extensively-drug resistant Mycobacterium tuberculosis: mutations versus efflux pumps
}

\author{
Hasan Ghajavand ${ }^{1,2}$, Mansour Kargarpour Kamakoli, ${ }^{1,2}$, Sharareh Khanipour ${ }^{1,2}$, Shahin Pourazar Dizaji 1,2, \\ Morteza Masoumi ${ }^{1,2}$, Fatemeh Rahimi Jamnani ${ }^{1,2}$, Abolfazl Fateh ${ }^{1,2}$, Mehdi Yaseri ${ }^{3}$, Seyed Davar Siadat ${ }^{1,2}$ and \\ Farzam Vaziri ${ }^{1,2^{*}}$
}

\begin{abstract}
Background: In order to shorten the course of treatment and its effectiveness, it is essential to gain an in-depth insight into the drug resistance mechanisms of Mycobacterium tuberculosis (M. tuberculosis).

Methods: In this study, we evaluated the contribution of 26 drug efflux pumps plus target gene mutations to the drug resistance levels in multi-drug resistant (MDR)/pre-extensively drug-resistant (pre-XDR)/extensively drugresistant (XDR) and mono-drug resistant clinical isolates of $M$. tuberculosis. The panels of $25 \mathrm{M}$. tuberculosis clinical strains were characterized for drug resistance-associated mutations with whole-genome sequencing and antibiotic profiles in the presence and absence of efflux inhibitor verapamil (VP).
\end{abstract}

Results: Different MICs were observed for the same target gene mutations. Out of the 16 MDR/pre-XDR/XDR isolates, 6 (37.5\%) and 3 (18.8\%) isolates demonstrated a significant decrease in rifampicin (RIF) MIC and isoniazid (INH) MIC due to the VP exposure $(64 \mu \mathrm{g} / \mathrm{mL})$, respectively. Susceptibility to RIF was fully restored in two isolates after VP exposure. Moreover, the efflux pump genes of Rv2938, Rv2936, Rv1145, Rv1146, Rv933, Rv1250, Rv876, Rv2333, Rv2459, Rv849, and Rv1819 were overexpressed in the presence of anti-TB drugs, showing the contribution of these efflux pumps to the overall resistance phenotype.

Conclusions: Our results clearly showed that efflux systems, besides spontaneous mutations, play a role in the development of INH/RIF resistance. In addition, although VP was effective in reducing the expression of some efflux pumps, it was not very successful at the phenotypic level.

Keywords: Tuberculosis, VP, Efflux pumps, MDR, Pre-XDR, XDR

\section{Background}

In recent years, tuberculosis (TB) has threatened communities all over the world and it is still one of the major public health concerns in many countries [1]. According to the latest report of the World Health Organization, the global incidence rate of $\mathrm{TB}$ is approximately 10 million

\footnotetext{
*Correspondence: farzam_vaziri@yahoo.com; f_vaziri@pasteur.ac.ir

'Department of Mycobacteriology and Pulmonary Research, Pasteur Institute of Iran, Tehran, Iran

${ }^{2}$ Microbiology Research Center (MRC), Pasteur Institute of Iran, No. 358, 12th

Farvardin Ave, Jomhoori St, Tehran 1316943551, Iran

Full list of author information is available at the end of the article
}

cases, of which 5.8 million (58\%) are men, 3.2 million (32\%) are women, and 1.0 million (10\%) are children [2]. Given the limited number of available anti-TB drugs, the emergence of multidrug-resistant TB (MDR-TB) and extensively drug-resistant TB (XDR-TB) has increased the complexity of designing appropriate treatment regimens. MDR-TB is caused by Mycobacterium tuberculosis (M. tuberculosis) that is resistant at least to isoniazid (INH) and rifampicin (RIF) while XDR-TB is caused by mycobacteria resistant to RIF and INH, along with fluoroquinolone and one of the three injectable drugs, namely capreomycin, kanamycin, and amikacin [3]. Resistance to anti-TB drugs

(c) The Author(s). 2019 Open Access This article is distributed under the terms of the Creative Commons Attribution 4.0 International License (http://creativecommons.org/licenses/by/4.0/), which permits unrestricted use, distribution, and 
is caused mainly by mutations in drug target genes [4], the impermeability of $M$. tuberculosis cell wall, and the activity of efflux pumps $[5,6]$. The presence of mutations in the target genes of antibiotics is considered the most important resistance mechanism in this bacterium [7].

Other mechanisms of resistance, such as efflux pumps, act synergistically with the permeability barrier to reduce the passage of antimicrobials across the bacterial outer membrane [8]. Previous studies have demonstrated that the resistance of $M$. tuberculosis is associated with constitutive or inducible expression of efflux systems $[9,10]$. Efflux pumps utilize the transmembrane electrochemical gradient of protons or sodium ions to extrude drugs from the cell, thereby neutralizing drug activity [11]. Efflux pumps are classified into six categories, including major facilitator superfamily (MFS), ATP-binding cassette $(A B C)$, small multidrug resistance (SMR), resistance-nodulation-division (RND), multidrug and toxic compound extrusion (MATE), and proteobacterial antimicrobial compound efflux (PACE) [12, 13]. MFS, ABC, RND, and SMR efflux pumps have been found in $M$. tuberculosis [14]. Efflux pumps usually confer low levels of drug resistance but play a significant role in evolving to high levels of resistance in $M$. tuberculosis [15].

Recently, efflux pump inhibitors (EPIs) have been demonstrated as a putative new drug compound, since these types of molecules bind to bacterial efflux pumps to inhibit their efflux function [16]. EPIs binding to $M$. tuberculosis efflux pumps were shown to inhibit the efflux of anti-TB drugs, enhance $M$. tuberculosis killing, reverse $M$. tuberculosis drug resistance, and produce synergistic effects with first-line anti-TB drugs $[17,18]$. Of the EPIs evaluated, verapamil (VP) has shown the most potent efflux inhibition. Studies with INH- or RIF-resistant clinical isolates demonstrated that the combined use of VP with INH or RIF reduced the minimum inhibitory concentration (MIC) of both drugs and reversed $M$. tuberculosis drug resistance against both drugs $[19,20]$.

In the current study, we (i) determined the MICs of anti-TB drugs, (ii) investigated the effect of VP on the MICs, and (iii) evaluated the expression of 26 genes encoding putative drug efflux pumps in selected MDR/pre-XDR/XDR and mono-resistant $M$. tuberculosis isolates.

\section{Methods}

\section{Bacterial strains and mutation analysis}

In this retrospective study 25 clinical isolates were used, 16 of which were MDR/pre-XDR/XDR and 9 isolates were mono-drug resistant ( 3 mono-RIF, 3 mono-INH, and 3 mono-EMB resistant isolates). $\mathrm{H} 37 \mathrm{Rv}$ strain and nine pan-susceptible clinical strains were also studied for comparison purposes. All of these isolates were collected, from January 2014 to January 2018, at the Department of Mycobacteriology and Pulmonary Research, Pasteur Institute of Iran. Whole genome sequencing data of all the isolates were available from our previous study [21]. The Ethics Committee of Pasteur Institute of Iran performed the ethical reviews, and written informed consents were obtained from the participants.

\section{Antimicrobial, EPI, and MIC agents}

Middlebrook 7H9 broth and albumin-dextrose-catalase (ADC) supplement were purchased from Difco (Detroit, MI, USA). INH, RIF, ethambutol (EMB), streptomycin (STR), ofloxacin (OFX), kanamycin (KAN), capreomycin (CAP), and VP were obtained from Sigma-Aldrich (St. Louis, MO, USA). All the solutions were prepared on the day of the experiment. Alamar blue was obtained from AbD Serotec (Oxford, UK).

\section{Conventional drug susceptibility testing}

Clinical isolates were re-confirmed for susceptibility to four first-line anti-TB drugs (i.e., INH, RIF, STR, and $\mathrm{EMB}$ ) and three second-line anti-TB drugs (i.e., KAN, OFX, and CAP) using a proportion method with Lowenstein-Jensen medium as described by the World Health Organization [19]. The drug concentrations in the medium were as follows: $0.2 \mu \mathrm{g} / \mathrm{mL}$ INH, $40 \mu \mathrm{g} / \mathrm{mL}$ RIF, $4 \mu \mathrm{g} / \mathrm{mL}$ STR, $2 \mu \mathrm{g} / \mathrm{mL}$ EMB, $30 \mu \mathrm{g} / \mathrm{mL}$ KAN, $2 \mu \mathrm{g} / \mathrm{mL}$ OFX, and $40 \mu \mathrm{g} / \mathrm{mL}$ CAP [22].

\section{Determination of MICs and VP effectiveness}

A microplate Alamar blue assay was performed as previously described to determine the MICs of all the 25 clinical isolates [23]. The effects of VP on the MICs of INH and RIF (for MDR/pre-XDR/XDR isolates) and INH, RIF, and EMB (for respective mono-resistant isolates) were also studied by incorporating the inhibitor at sub-inhibitory concentrations in $M$. tuberculosis cultures in the assay. Two-fold serial dilutions of RIF (concentration range of $0.001-128 \mu \mathrm{g} / \mathrm{mL}), \mathrm{INH}(0.001-256 \mu \mathrm{g} / \mathrm{mL})$, and EMB $(0.1-50 \mu \mathrm{g} / \mathrm{mL})$ were made directly in the wells in the absence or presence of $64 \mu \mathrm{g} / \mathrm{mL}$ of VP. The concentration of VP $(16-128 \mu \mathrm{g} / \mathrm{mL})$ was determined after studying the effect of concentration-dependent titration using this inhibitor on a certain MDR isolate. In addition, in a previous study, the $64 \mu \mathrm{g} / \mathrm{mL}$ concentration was proven as the ideal concentration [24].

MIC was defined as the lowest drug concentration preventing a change in color. Isolates with MICs of INH $<0.25 \mu \mathrm{g} / \mathrm{ml}$, RIF $<1 \mu \mathrm{g} / \mathrm{ml}$, and $\mathrm{EMB} \leq 2.5 \mu \mathrm{g} / \mathrm{ml}$ were defined as being susceptible to INH, RIF, and EMB, respectively [23]. All the tests for each strain were carried out at least in duplicate to calculate the mean MIC for each strain. 


\section{Expression profile of drug efflux pumps}

To extract the total bacterial RNA, M. tuberculosis clinical isolates were cultured in $10 \mathrm{~mL}$ of Middlebrook $7 \mathrm{H} 9$ broth (BD) with ADC supplement for the $16 \mathrm{MDR} /$ pre-XDR/XDR and 9 mono-drug resistant isolates. RIF, $\mathrm{INH}, \mathrm{EMB}, \mathrm{RIF}+\mathrm{VP}, \mathrm{INH}+\mathrm{VP}$, and $\mathrm{EMB}+\mathrm{VP}$ were added to these cultures individually at sub-inhibitory concentrations (half of the MIC), incubated at $37^{\circ} \mathrm{C}$ for 25 days, and collected for RNA extraction. The total bacterial RNA was isolated using PREP-NA DNA/RNA extraction kit according to the manufacturer's instructions. The quality and integrity of total RNA were assessed using a nanophotometer.

After treatment with DNase I (Invitrogen), RNA $(1 \mu \mathrm{g})$ was submitted to cDNA synthesis according to the manufacturer's recommendations (PrimeScript ${ }^{\mathrm{Tm}}$ 1st strand cDNA Synthesis Kit, TAKARA). Quantitative reverse transcription PCR was performed in a $20-\mu$ l system containing $10 \mu \mathrm{l}$ of $2 \times$ mixture supplied with SYBR Green, $100 \mathrm{ng}$ of complementary DNA template, and $5 \mathrm{pmol}$ of each primer set. The primer sets and sequences of oligonucleotides are described elsewhere [24]. To assure specific amplification, the melting curves of each reaction were assessed and each sample was performed in duplicate. polA and $\sec A$ were used as the housekeeping genes for normalization. The quantification of target gene expression in induced strains relative to non-induced strains was performed by the $2^{-\Delta \Delta \mathrm{Ct}}$ method using the GenEx 6 software [25]. An expression equal to 1 indicated identical expression levels, an expression $\geqslant 4$ indicated up-regulation, and an expression $\leq 4$ indicated down-regulation [24].

\section{Statistical analysis}

The Wilcoxon signed-rank test was used to evaluate the expression changes in the same isolate due to exposure to VP (in addition to the conventional drug). We used the linear mixed model (LMM) to assess the difference in the expression rates of various types of genes within the same isolate. All the statistical analyses were performed in IBM SPSS statistics for Windows version 25.0 software (IBM Corp. Released 2017, Armonk, NY). A $P$-value of less than 0.05 was considered statistically significant.

\section{Results}

\section{MICs and the effect of VP}

Among the $16 \mathrm{MDR} /$ pre-XDR/XDR-TB clinical isolates, PII-30 and PII-33 were resistant to all the antibiotics tested, 10 isolates were resistant to all the first-line drugs (i.e., STR, INH, RIF, and EMB), and the remaining isolates were resistant to at least two of the first-line drugs. The INH MICs of the $16 \mathrm{MDR} /$ pre-XDR/XDR isolates varied from 2 to $64 \mu \mathrm{g} / \mathrm{mL}$, whereas the RIF MICs varied from 4 to $128 \mu \mathrm{g} / \mathrm{mL}$ (Table 1 ).

Out of the $16 \mathrm{MDR} / \mathrm{pre}-\mathrm{XDR} / \mathrm{XDR}$ isolates, 6 (37.5\%) and $3(18.8 \%)$ isolates demonstrated significant reductions $(P<0.05)$ in RIF MICs and INH MICs after VP exposure, respectively. Susceptibility to RIF was fully restored $(\mathrm{MIC}=0.25 \mu \mathrm{g} / \mathrm{mL}$ ) in two isolates (i.e., PII-27 and PII-28) after VP exposure.

Of the nine mono-drug resistant clinical isolates, three were resistant to RIF, three were resistant to INH, and three were resistant to EMB. The highest MIC $(128 \mu \mathrm{g} /$ $\mathrm{mL}$ ) was related to the PII-4 strain (mono-RIF resistant isolate). Only in PII-15 (mono-EMB resistant isolate) was observed a two-fold decrease in MIC in the presence of VP (Table 2).

\section{Gene mutation analysis}

The whole genome sequencing revealed that all the MDR/pre-XDR/XDR-TB isolates had the katG S315 T mutation, except PII-26 that was identified to have a combination of katG $\mathrm{N} 138 \mathrm{H}$ and $a h p C \mathrm{t}-76 \mathrm{a}$ mutations and the highest MIC $(64 \mu \mathrm{g} / \mathrm{mL})$ compared to other MDR/pre-XDR/XDR strains. The RIF resistance in all the MDR/pre-XDR/XDR strains was attributed to mutations in the rpoB hot-spot region (S450 L mutation) (Table 1). Among the nine mono-resistant clinical isolates, all the mono-RIF resistant isolates had the S450 L mutation in rpoB. Regarding the three mono-INH resistant isolates, only harbored two isolates the katG S315 T mutation, and PII-9 did not have any related mutations. No mutations at $e m b A$ or $e m b B$ were detected in the mono-EMB resistant clinical isolates (Table 2).

\section{Expression profile of drug efflux pumps}

According to Table 1, $10 \mathrm{MDR} / \mathrm{pre}-\mathrm{XDR} / \mathrm{XDR}$ isolates had at least one gene overexpressed under RIF and INH stress ( $\geqslant$ four-fold induction). Among the $16 \mathrm{MDR} /$ pre-XDR/XDR isolates, there were two isolates (PII-31 and PII-20) and one isolate (PII-28) with the overexpression of eight and seven efflux pump genes under RIF and INH stress, respectively. In addition, 11 and 9 isolates under RIF + VP and INH + VP stress showed a four-fold down-regulation in at least one of these 26 studied genes, respectively.

Among the nine mono-drug resistant clinical isolates, PII-4, PII-8, PII-9, PII-10, and PII-11 showed no induction in any of the 26 efflux pump genes under RIF and INH stress. Of the nine mono-drug resistant isolates, four isolates overexpressed one or two of the following genes: $R v 1250, R v 876, R v 3239, R v 2459, R v 2456, R v 2846$, and $R v 2938$. Moreover, among the 26 tested efflux pump genes, $R v 2938$ was down-regulated more than four folds under RIF + VP, INH + VP, and EMB + VP stress in three isolates (Table 2). 
Table 1 Drug susceptibility profile, MIC results, VP treatment, efflux pump expression and mutations in 16 MDR/pre-XDR and XDR isolates

\begin{tabular}{|c|c|c|c|c|c|c|c|c|c|c|c|c|c|c|c|c|c|c|}
\hline \multirow{2}{*}{$\begin{array}{l}\text { Sample } \\
\text { ID }\end{array}$} & \multirow{2}{*}{$\underline{\mathbf{z}}$} & \multirow[b]{2}{*}{ 唇 } & \multirow[b]{2}{*}{ 暗 } & \multirow{2}{*}{\multicolumn{2}{|c|}{ : }} & \multirow[b]{2}{*}{ | } & \multirow[b]{2}{*}{ है। } & \multirow{2}{*}{$\begin{array}{l}\text { MIC } \\
\text { RIF }\end{array}$} & \multirow{2}{*}{$\begin{array}{c}\text { RIF } \\
+ \\
\text { VP }\end{array}$} & \multirow{2}{*}{$\begin{array}{l}\text { MIC } \\
\text { INH }\end{array}$} & \multirow{2}{*}{$\begin{array}{l}\text { INH } \\
+ \\
\text { VP }\end{array}$} & \multirow{2}{*}{$\begin{array}{l}\text { Genes } \\
\text { overexpressed } \\
\text { under RIF } \\
\text { stress }\end{array}$} & \multirow{2}{*}{$\begin{array}{l}\text { Genes overexpressed } \\
\text { under INH } \\
\text { stress }\end{array}$} & \multirow{2}{*}{$\begin{array}{c}\text { Genes } \\
\text { down } \\
\text { regulated } \\
\text { under } \\
\text { VP+RIF } \\
\text { stress }\end{array}$} & \multirow{2}{*}{$\begin{array}{l}\text { Genes down } \\
\text { regulated } \\
\text { under V VP+ INH } \\
\text { stress }\end{array}$} & \multicolumn{3}{|c|}{ Mutations } \\
\hline & & & & & & & & & & & & & & & & $r p o B$ & inhA or ahpC & katG \\
\hline PII-20 & $\mathrm{R}$ & $\mathrm{R}$ & $\mathrm{R}$ & $\mathrm{R}$ & s & s & s & 64 & 16 & 32 & 4 & 3239 & $\begin{array}{l}2994-3239-2846-2459- \\
2456-849-1819\end{array}$ & $*$ & $\begin{array}{c}783-2846-2459- \\
2937-849-1819-2333\end{array}$ & $\mathrm{~S} 450 \mathrm{~L}(\mathrm{tgg} / \mathrm{Tg})$ & & S315T (agc/aCc) \\
\hline PII-21 & $\mathrm{R}$ & $\mathrm{R}$ & $\mathrm{R}$ & s & s & s & $\mathrm{R}$ & 64 & 64 & 4 & 4 & 2936 & $783-2936$ & $1672-1145$ & 933-783 & $\mathrm{S} 450 \mathrm{~L}(\mathrm{tcg} / \mathrm{Tg}$ ) & & $\mathrm{S} 315 \mathrm{~T}(\mathrm{agc} / \mathrm{aCc})$ \\
\hline PII-22 & $\mathrm{R}$ & $\mathrm{R}$ & $\mathrm{R}$ & $\mathrm{s}$ & $\mathrm{s}$ & s & $\mathrm{R}$ & 32 & 32 & 2 & 2 & * & $933-842$ & 1634-1672 & $933-842$ & $\mathrm{~S} 450 \mathrm{~L}(\mathrm{tgg} / \mathrm{tg})$ & & S315T (agc/acc) \\
\hline PII-23 & $\mathrm{R}$ & $\mathrm{R}$ & $\mathrm{R}$ & $\mathrm{R}$ & $\mathrm{R}$ & $\mathrm{s}$ & $\mathrm{R}$ & 8 & 8 & 4 & 4 & 2938 & * & 2938 & * & $\mathrm{S} 450 \mathrm{~L}(\mathrm{tg} / \mathrm{tTg})$ & & S315T (agc/aCc) \\
\hline PII-24 & $\mathrm{R}$ & $\mathrm{R}$ & $\mathrm{R}$ & $\mathrm{R}$ & $\mathrm{R}$ & $\mathrm{s}$ & $\mathrm{R}$ & 32 & 32 & 2 & 2 & 876 & * & $876-1410$ & * & $\mathrm{S} 450 \mathrm{~L}(\mathrm{tgg} / \mathrm{tg})$ & & S315T (agc/aCc) \\
\hline PII-25 & $\mathrm{R}$ & $\mathrm{R}$ & $\mathrm{R}$ & $\mathrm{R}$ & $\mathrm{R}$ & s & $\mathrm{R}$ & 64 & 64 & 4 & 4 & * & $2333-2938$ & 2333 & 2333-1410 & $\mathrm{S} 450 \mathrm{~L}(\mathrm{tcg} / \mathrm{Tg} \mathrm{g}$ & & S315T (agc/aCc) \\
\hline PII-26 & $\mathrm{R}$ & $\mathrm{R}$ & $\mathrm{s}$ & $\mathrm{s}$ & $\mathrm{s}$ & $\mathrm{R}$ & $\mathrm{R}$ & 64 & 64 & 64 & 64 & $*$ & $1250-1410-2938$ & * & 2938 & $\mathrm{~S} 450 \mathrm{~L}(\mathrm{tcg} / \mathrm{Tg})$ & ahpC-76 att & $\begin{array}{c}\mathrm{N} 138 \mathrm{H} \\
(\mathrm{aac} / \mathrm{Cac})\end{array}$ \\
\hline PII-27 & $\mathrm{R}$ & R & $\mathrm{R}$ & $\mathrm{R}$ & $\mathrm{R}$ & $\mathrm{s}$ & $\mathrm{R}$ & 128 & 0.25 & 16 & 0.25 & $\begin{array}{c}933-1250-2936- \\
1410-2938\end{array}$ & 2936-1410 & $\begin{array}{c}842-3239- \\
3065\end{array}$ & 933-2936 & S450L (tcg/Tg) & & S315T (agc/aCc) \\
\hline PII-28 & $\mathrm{R}$ & $\mathrm{R}$ & $\mathrm{s}$ & $\mathrm{R}$ & $\mathrm{s}$ & $\mathrm{s}$ & $\mathrm{R}$ & 4 & 0.25 & 2 & 2 & $\begin{array}{l}\begin{array}{l}1145-3239- \\
3065-1672\end{array} \\
3\end{array}$ & $\begin{array}{c}1145-3239-2333-876- \\
3065-2936-1672\end{array}$ & 1146 & $2846-3065$ & $\mathrm{~S} 450 \mathrm{~L}(\mathrm{tcg} / \mathrm{tTg})$ & & S315T (agc/aCc) \\
\hline PII-29 & $\mathrm{R}$ & R & $\mathrm{R}$ & $\mathrm{R}$ & $\mathrm{s}$ & R & R & 32 & 16 & 16 & 16 & $*$ & * & * & $\begin{array}{c}\text { 783-1250-849-2333- } \\
2936-2938\end{array}$ & $\mathrm{~S} 450 \mathrm{~L}(\mathrm{tcg} / \mathrm{Tg})$ & $\mathrm{N} 231 \mathrm{D}(\mathrm{aac} / \mathrm{Gac})$ & $\mathrm{S} 315 \mathrm{~T}(\mathrm{agc} / \mathrm{aCc})$ \\
\hline PII-30 & $\mathrm{R}$ & $\mathrm{R}$ & $\mathrm{R}$ & $\mathrm{R}$ & $\mathrm{R}$ & $\mathrm{R}$ & $\mathrm{R}$ & 64 & 64 & 32 & 8 & * & * & * & * & $\mathrm{S} 450 \mathrm{~L}(\mathrm{tg} / \mathrm{t} \mathrm{Tg})$ & & S315T (agc/aCc) \\
\hline PII-31 & $\mathrm{R}$ & $\mathrm{R}$ & $\mathrm{R}$ & $\mathrm{R}$ & $\mathrm{s}$ & $\mathrm{R}$ & $\mathrm{R}$ & 32 & 32 & 8 & 8 & $\begin{array}{c}1146-2459- \\
2333-876-3065- \\
1410-1672-1145\end{array}$ & 933-1146-1634-2938 & 1672 & $\begin{array}{l}783-1250-2846- \\
2936-1672-2938\end{array}$ & $\mathrm{~S} 450 \mathrm{~L}(\mathrm{tcg} / \mathrm{tg})$ & N231D (aac/Gac) & S315T (agc/aCc) \\
\hline PII-32 & $\mathrm{R}$ & $\mathrm{R}$ & $\mathrm{R}$ & $\mathrm{R}$ & $\mathrm{s}$ & $\mathrm{s}$ & $\mathrm{s}$ & 128 & 64 & 4 & 4 & * & * & $*$ & * & $\mathrm{S} 450 \mathrm{~L}(\mathrm{tgg} / \mathrm{Tg})$ & & S315T (agc/aCc) \\
\hline PII-33 & $\mathrm{R}$ & $\mathrm{R}$ & $\mathrm{R}$ & $\mathrm{R}$ & $\mathrm{R}$ & $\mathrm{R}$ & $\mathrm{R}$ & 64 & 64 & 4 & 4 & $\begin{array}{l}\text { 933-1250-2846- } \\
2938\end{array}$ & 933-1146-2938-1145 & $\begin{array}{l}1250-2846- \\
2936\end{array}$ & $*$ & $\mathrm{~S} 450 \mathrm{~L}(\mathrm{tcg} / \mathrm{Tg} \mathrm{g})$ & & $\mathrm{S} 315 \mathrm{~T}(\mathrm{agc} / \mathrm{aCc})$ \\
\hline PII-35 & $\mathrm{R}$ & $\mathrm{R}$ & $\mathrm{R}$ & $\mathrm{R}$ & $\mathrm{s}$ & $\mathrm{R}$ & $\mathrm{s}$ & 8 & 8 & 4 & 4 & 933 & $*$ & 933 & * & $\mathrm{S} 450 \mathrm{~L}(\mathrm{tcg} / \mathrm{tg})$ & N231D (aac/Gac) & S315T (agc/acc) \\
\hline PII-36 & $\mathrm{R}$ & $\mathrm{R}$ & $\mathrm{R}$ & $\mathrm{R}$ & $\mathrm{s}$ & $\mathrm{s}$ & $\mathrm{s}$ & 8 & 4 & 2 & 2 & $2936-2938$ & 2938 & $\begin{array}{l}933-2936- \\
2938\end{array}$ & * & $\mathrm{S} 450 \mathrm{~L}(\mathrm{tcg} / \mathrm{Tg})$ & & S315T (agc/acc) \\
\hline
\end{tabular}

*: not changed

INH Isoniazid, RIF Rifampicin, EMB Ethambutol, CAP Capreomycin, KAN Kanamycin, STR Streptomycin, OFX Ofloxacin, VP Verapamil, S Susceptible, $R$ Resistant, MIC Minimum inhibitory concentration

Additional data regarding drug susceptibility, MIC results, VP treatments, efflux pump expression, and mutations are provided in Table 1 (for MDR/pre-XDR/XDR) and Table 2 (for mono-resistant isolates). The differential expression of efflux pump genes is provided in Additional file 1: Tables S1 and S2.

\section{Discussion}

In order to shorten the course of treatment and its effectiveness, it is essential to gain an in-depth insight into the drug resistance mechanisms of $M$. tuberculosis [26]. Although drug resistance is acquired mainly due to mutational modifications of the drug target, it has become

Table 2 Drug susceptibility profile, MIC results, VP treatment, efflux pump expression and mutations in 9 mono drug resistant isolates

\begin{tabular}{|c|c|c|c|c|c|c|c|c|c|c|c|c|c|c|c|c|}
\hline \multirow{2}{*}{$\begin{array}{l}\text { Sample } \\
\text { ID }\end{array}$} & \multirow{2}{*}{$\overline{\underline{Z}}$} & \multirow{2}{*}{ 贸 } & \multirow{2}{*}{ 咅 } & \multirow{2}{*}{$\sum^{\infty}$} & \multirow{2}{*}{$\underline{\Sigma}$} & \multirow{2}{*}{ 希 } & \multirow{2}{*}{ ì } & \multirow{2}{*}{ MIC } & \multirow{2}{*}{$\mathrm{MIC}+\mathrm{VP}$} & \multirow{2}{*}{$\begin{array}{c}\text { Genes } \\
\text { overexpressed } \\
\text { under D stress* }\end{array}$} & \multirow{2}{*}{$\begin{array}{l}\text { Genes down } \\
\text { regulated under } \\
\text { D+VP stress* }\end{array}$} & \multicolumn{5}{|c|}{ Mutations } \\
\hline & & & & & & & & & & & & $k a t G$ & fabGl_inhA_prom & rpoB & $e m b B$ & $e m b A$ \\
\hline PII-4 & $\mathrm{s}$ & $\mathrm{R}$ & s & $\mathrm{S}$ & $\mathrm{S}$ & $\mathrm{s}$ & $\mathrm{S}$ & MIC RIF $=128$ & $\mathrm{MIC}$ RIF +VP= 128 & $*$ & $*$ & & & $\begin{array}{c}\mathrm{S} 450 \mathrm{~L} \\
(\mathrm{tcg} / \mathrm{Tg})\end{array}$ & & \\
\hline PII-7 & $\mathrm{s}$ & $\mathrm{R}$ & $\mathrm{s}$ & $\mathrm{s}$ & $\mathrm{S}$ & $\mathrm{s}$ & $\mathrm{s}$ & MIC RIF = 32 & MIC RIF +VP= 32 & $1250-876$ & $1250-876$ & & & $\begin{array}{l}\mathrm{S} 450 \mathrm{~L} \\
(\mathrm{tcg} / \mathrm{Tg})\end{array}$ & & \\
\hline PII-8 & $\mathrm{S}$ & $\mathrm{R}$ & $\mathrm{s}$ & $\mathrm{S}$ & $\mathrm{S}$ & $\mathrm{S}$ & $\mathrm{S}$ & MIC RIF $=32$ & $\mathrm{MIC}$ RIF + VP= 32 & * & $*$ & & & $\begin{array}{c}\mathrm{S} 450 \mathrm{~L} \\
(\mathrm{tcg} / \mathrm{Tg})\end{array}$ & & \\
\hline PII-9 & $\mathrm{R}$ & $\mathrm{s}$ & $\mathrm{s}$ & $\mathrm{s}$ & $\mathrm{s}$ & $\mathrm{s}$ & $\mathrm{s}$ & MIC INH = 1 & $\mathrm{MIC} I \mathrm{INH}+\mathrm{VP}=1$ & * & $\begin{array}{c}933-3239-2846- \\
2456-2938\end{array}$ & & $-15 \mathrm{c} / \mathrm{t}$ & & & \\
\hline PII-10 & $\mathrm{R}$ & S & $\mathrm{s}$ & $\mathrm{S}$ & S & $\mathrm{S}$ & $\mathrm{S}$ & $\mathrm{MIC}$ INH $=4$ & $\mathrm{MIC} I \mathrm{INH}+\mathrm{VP}=4$ & $*$ & 933 & $\begin{array}{c}\mathrm{S} 315 \mathrm{~T} \\
(\mathrm{agc} / \mathrm{aCc})\end{array}$ & & & & \\
\hline PII-11 & $\mathrm{R}$ & $\mathrm{S}$ & $\mathrm{s}$ & $\mathrm{S}$ & S & $\mathrm{S}$ & $\mathrm{s}$ & MIC INH = 4 & $\mathrm{MIC} I N H+V P=4$ & $*$ & $*$ & $\begin{array}{c}\mathrm{S} 315 \mathrm{~T} \\
(\mathrm{agc} / \mathrm{aCc})\end{array}$ & & & & \\
\hline PII-15 & $\mathrm{s}$ & $\mathrm{s}$ & $\mathrm{s}$ & $\mathrm{R}$ & $\mathrm{S}$ & $\mathrm{s}$ & $\mathrm{s}$ & $\begin{array}{c}\text { MIC EMB = } \\
3.125\end{array}$ & $\mathrm{MIC} \mathrm{EMB}+\mathrm{VP}=1.56$ & 3239 & 2937 & & & & & \\
\hline PII-17 & $\mathrm{s}$ & $\mathrm{S}$ & $\mathrm{s}$ & $\mathrm{R}$ & $\mathrm{s}$ & $\mathrm{s}$ & $\mathrm{s}$ & $\begin{array}{c}\text { MIC EMB }= \\
3.125\end{array}$ & $\mathrm{MIC}$ EMB $+\mathrm{VP}=3.125$ & $2459-2456$ & 2938 & & & & & \\
\hline PII-18 & $\mathrm{s}$ & $\mathrm{s}$ & $\mathrm{s}$ & $\mathrm{R}$ & $\mathrm{S}$ & $\mathrm{s}$ & $\mathrm{s}$ & $\begin{array}{l}\text { MIC EMB = } \\
3.125\end{array}$ & $\mathrm{MIC} E M B+\mathrm{VP}=3.125$ & $1250-2846-2938$ & $1250-2938$ & & & & & \\
\hline
\end{tabular}


clear that multi-drug efflux systems may play roles in the drug resistance of M. tuberculosis, as well [27].

In the current study conducted at the phenotypic level, an efflux pump inhibitor, VP, exerted a significant effect on the reduction of RIF MIC and INH MIC in 37.5 and $18.8 \%$ of the MDR/pre-XDR/XDR isolates, respectively. Two isolates (PII-27 and PII-28) merely showed susceptibility to RIF after the VP exposure. Among the mono-resistant isolates, the MIC reduction in the presence of VP was observed in only one mono-EMB resistant isolate (i.e., PII-15). Collectively, the current study showed that VP partially restored the potency of RIF, INH, and EMB against drug-resistant M. tuberculosis isolates but not as successful as previous studies [16, 24, 28]. Recently, it was shown that VP does not affect intracellular anti-TB drug uptake and accumulation in $M$. tuberculosis through the direct inhibition of efflux pumps; instead, it targets membrane energetics in the bacterium [29]. However, this issue needs further investigations.

We investigated mutations in target genes, the expression levels of 26 genes encoding putative drug efflux transporters under drug stress, and efflux inhibition with VP at the mRNA level. Most of the MDR/pre-XDR/XDR isolates in our study had the katG $\mathrm{S} 315 \mathrm{~T}$ and $r p o B$ S450 L mutations. It seems that these mutations play a pivotal role in INH and RIF resistance, respectively. As demonstrated in Table 1, MDR/pre-XDR/XDR isolates were similarly ( 10 vs. 10$)$ induced by RIF and INH to overexpress efflux pump genes, but more genes were induced by INH than by RIF (34 vs. 28). Li et al. reported that the expression levels of genes in response to INH were significantly higher in MDR than in RIF-resistant isolates. Additionally, more genes were expressed in response to INH compared to RIF [30], suggesting that more efflux pumps may respond to INH than to RIF in MDR/pre-XDR/XDR M. tuberculosis. Our study showed that some of these genes fail to be up-regulated in any of the MDR/pre-XDR/XDR isolates after RIF/INH treatment. In addition, $\mathrm{Li}$ et al. reported that $R v 1258$ (tap) and $R v 2265$ by INH and $R v 783$ (emrB), Rv1258, Rv2994, $R v 2456, R v 2265$, and $R v 849$ by RIF were not overexpressed in any of the MDR isolates, which was consistent with the results of our study [30].

$\mathrm{ABC}$ transporters constitute a large superfamily of proteins, which are able to import or export a wide range of substances, including amino acids, ions, sugars, lipids, and drugs. In addition, they are involved in the determination of intrinsic levels of resistance in $M$. $t u$ berculosis $[31,32]$. The $d r r$ (doxorubicin resistance) operon was first identified in Streptomyces peucetius [33]. The $d r r A, d r r B$, and $d r r C$ efflux pump are parts of the $\mathrm{ABC}$ transporter complex involved in doxorubicin resistance [34]. In this study, $d r r C(R v 2938)$ had the highest expression level compared to other genes in the 16
$\mathrm{MDR} /$ pre-XDR/XDR isolates, as it was overexpressed in 4 (25\%) and 5 (31\%) isolates under RIF and INH stress, respectively. On the other hand, the VP-treated MDR/ pre-XDR/XDR isolates could down-regulate the $d r r C$ efflux gene more remarkably than most other genes. In this study, we revealed that only 1 out of the 9 mono-resistant isolates overexpressed $d r r C$; whereas, this efflux pump was down-regulated by 3/9 VP-treated mono-resistant isolates. Additionally, in the mono-resistant isolates, $R v 2938$ had the highest down-regulation compared to other genes. Gupta et al. demonstrated that $R v 2938$ played a potent role in drug resistance, especially toward EMB and STR [35]. The PII36 isolate showed the upregulation of the efflux gene $d r r C$ by INH and RIF and down-regulation in the presence of RIF + VP. The results of our study suggest that $d r r C$ plays an important role in the INH/RIF resistance in M. tuberculosis.

Choudhuri et al. showed that $\operatorname{dr} A B$ was expressed in Mycobacterium smegmatis, which can contribute to the resistance to EMB, STR, norfloxacin, erythromycin, tetracycline, and chloramphenicol [36]. Our study revealed that RIF and INH induced a four-fold increase in $d r r A$ (Rv2936) expression in 3 out of $16 \mathrm{MDR} / \mathrm{pre}-\mathrm{XDR} / \mathrm{XDR}$ isolates. However, we found that $\operatorname{dr} A$ was down-regulated in 2 and $3 \mathrm{MDR} /$ pre-XDR/XDR isolates with $\mathrm{VP}+\mathrm{RIF}$ and $\mathrm{VP}+\mathrm{INH}$ treatment, respectively. Additionally, our study showed that $d r r A$ could be up-regulated and down-regulated in PII27 (by INH and RIF) and PII36 (by $\mathrm{VP})$ isolates, respectively. In the presence of VP, the MIC of INH $(16 \mu \mathrm{g} / \mathrm{ml})$ reduced by 64 folds $(0.25 \mu \mathrm{g} / \mathrm{ml})$ in isolate PII27, which showed that the efflux activity could be inhibited by VP. In contrast, our study suggested that $d r r A$ failed to be up-regulated or down-regulated with VP treatment in mono-drug resistant isolates, demonstrating that $d r r A$ may be one of the drug resistance factors in MDR/ pre-XDR/XDR isolates, with no significant contribution to resistance in mono-resistant isolates.

Pang et al. showed that $d r r A$ might be involved in one of the RIF-related efflux pumps in mono-resistant isolates, which was not consistent with our results [37]. In a similar study, $\mathrm{Li}$ et al. reported that $\operatorname{drr} B$ was up-regulated in 4 and 2 out of 9 MDR isolates in response to INH and RIF, respectively [30]. Our results demonstrated that $\operatorname{drr} B(R v 2937)$ failed to be up-regulated in any of the MDR/pre-XDR/XDR isolates by RIF and INH, while $d r r B$ was down-regulated in one and none of these MDR/pre-XDR/XDR isolates in response to INH + VP and RIF + VP stress, respectively. In spite of the down-regulation of $d r r B$ after VP exposure in one of the nine isolates, among the mono-drug resistant isolates, none was significantly up-regulated with RIF, INH, and EMB treatment.

RND transporter as a part of the efflux pump contributes to the $M$. tuberculosis drug resistance. Recently, 
among the RND transporters, $M m p L$ has emerged as an essential key in the elaboration of the cell envelope of mycobacteria. Moreover, a few $M m p L$ proteins, such as $M m p L 5$, have been demonstrated to participate in the active efflux of antitubercular drugs [38]. mmpL13a (Rv1145) and mmpL13b (Rv1146) have been shown to be the variants of an individual gene in the $\mathrm{H} 37 \mathrm{Rv}$ strain of $M$. tuberculosis although $14 \mathrm{mmpL}$ genes have been discovered in the $M$. tuberculosis genome [39]. Our study demonstrated that among $16 \mathrm{MDR} / \mathrm{pre}-\mathrm{XDR} / \mathrm{XDR}$ isolates, $m m p L 13 a$ and $m m p L 13 b$ were individually overexpressed under INH stress in two strains (PII-28 and PII-31) while they were co-expressed in the PII-33 isolate.

$m m p L 13 a$ and $m m p L 13 b$ were also up-regulated in two and one MDR/pre-XDR/XDR isolates under RIF stress, respectively. This result was not consistent with the findings of a previous report [30]. However, mmpL13a and $m m p L 13 b$ were independently down-regulated in two and none of these MDR/pre-XDR/XDR isolates in response to RIF + VP and INH + VP stress, respectively. On the other hand, $m m p L 13 a$ and $m m p L 13 b$ were not up- or downregulated in any of the nine mono-resistant isolates after RIF, INH, EMB, and VP exposure. This result suggests, for the first time, that $m m p L 13 a$ and $m m p L 13 b$ have higher expression rates in MDR/pre-XDR/XDR isolates compared to mono-drug resistant isolates under RIF and INH stress.

Our study showed that the high-level expression of two specific genes in the MFS, i.e., Rv1250 and Rv876, occurred in two and one of the MDR/pre-XDR/XDR isolates under RIF and INH stress, respectively. On the other hand, efflux pumps $R v 1250$ and $R v 876$ were down-regulated under VP + RIF stress in one isolate; however, in this study, we revealed that $R v 1250$ and Rv876 were down-regulated by VP + INH treatment in two and none of the MDR/pre-XDR/XDR isolates, respectively.

Contrary to our findings, Narang et al. reported that $R v 1250$ and $R v 876$ were not overexpressed in any of the MDR isolates due to INH stress [9]. In this study, we revealed that among mono-resistant isolates, only were $R v 1250$ and $R v 876$ co-overexpressed in the PII-7 isolate in response to RIF. Isolate PII-7 also showed a significant reduction in the expression of $R v 1250$ and $R v 876$ in the presence of VP, suggesting the role of $R v 1250$ and $R v 876$ in the RIF resistance of the PII-7 isolate. EfpA (Rv2846c), another efflux transporter of the MFS family, was overexpressed in two MDR/pre-XDR/XDR isolates (PII-20 and PII-33) in response to RIF or INH stress and in one mono-resistant isolate (PII-18) in response to EMB. The PII-20 isolate showed down-regulation of the efflux genes $R v 2846 c, R v 2459, R v 849$, and $R v 1819$, as well as a drastic eight-fold reduction in the MIC of INH in the presence of VP, confirming the role of efflux pumps in the INH resistance in this isolate. However, Machado et al. found that EfpA was upregulated independently of the exposure drugs, which is in concordance with our findings [40].

The efflux pump protein $R v 933$ (pstB) was also categorized into the $A B C$ transporter family [37]. Our results demonstrated that $R v 933$ was overexpressed in three of these MDR/pre-XDR/XDR isolates under RIF and INH stress. Besides, Rv933 was down-regulated with RIF + VP and INH + VP treatment respectively in two and three of these MDR/pre-XDR/XDR isolates. Although Rv933 failed to be up-regulated in any of the mono-resistant isolates with RIF, INH, and EMB treatment, $R v 933$ was down-regulated in two out of nine mono/poly drug-resistant isolates. In another study conducted by $\mathrm{Oh}$ et al., it was reported that the enhanced expression of $p s t B$ in clinical drug-resistant tuberculosis isolates may contribute to drug resistance in M. tuberculosis [41]. However, in this study, we showed that the expression of $R v 1250$, $R v 3239, R v 3065$, and $R v 1672$ in the presence of RIF and $R v 1410, R v 3239$, and $R v 2333$ in the presence of INH significantly increased in two MDR/PRE-XDR/XDR isolates. Interestingly, the isolate PII-25 overexpressed the $R v 2333$ (stp) gene due to INH treatment and down-regulated it in the presence of INH + VP, indicating that this gene is involved in the efflux of INH. Regarding the isolate PII-27 with high initial resistance to RIF (MIC $128 \mu \mathrm{g} / \mathrm{ml}$ ), we observed that the RIF MIC reduced (MIC $0.25 \mu \mathrm{g} / \mathrm{ml}$ ) in the presence of VP, implying the overexpression of efflux genes Rv933, Rv1250, Rv2936, Rv1410, and $R v 2938$ in response to RIF stress. On the contrary, none of these genes was down-regulated by RIF + VP. We speculate that other efflux genes are involved in the development of resistance in this strain. Surprisingly, the isolate PII-18, with resistance to EMB (MIC $3.125 \mu \mathrm{g} / \mathrm{mL}$ ) and no mutations at $e m b A$ or $e m b B$, showed the overexpression of three efflux genes (i.e., $R v 1250, R v 2846$, and $R v 2938$ ) in response to EMB stress. On the other hand, the isolate PII-18 showed a significant reduction in the expression of $R v 1250$ and $R v 2938$ in the presence of VP, suggesting the role of $R v 1250$ and $R v 2938$ in EMB resistance in the PII-18 isolate.

The Mmr efflux transporter ( $R v 3065)$ is the only efflux pump from the SMR family presented in the M. tuberculosis genome [42]. We found that this efflux pump was overexpressed in two MDR/pre-XDR/XDR isolates (i.e., PII-28 and PII-31) in response to RIF or INH. The MIC of RIF in the PII-28 isolate reduced by 16 folds in the presence of VP; this efflux pump was among the genes down-regulated under VP treatment.

\section{Conclusion}

Our results clearly show that efflux systems play a role, besides spontaneous mutations, in the development of 
INH/RIF resistance. Moreover, there were some associations between $R v 2938, R v 2936, R v 1145, R v 1146$, and Rv933 genes and INH/RIF drugs in the current study. In addition, a similar association was noted between $R v 1250$ and $R v 2938$ genes and EMB. A direct association was also found between $R v 1250$ and $R v 876$ genes and RIF resistance, as well as between $R v 2333(s t p), R v 2846 c$, $R v$ 2459, $R v$ 849, and $R v 1819$ genes and INH resistance. Finally, although VP was effective in reducing the expression of some efflux pumps, it was not very successful at the phenotypic level. Determining Time-Kill Curves and in vivo studies are required to confirm our results. More importantly, in spite of the fact that VP is approved by the FDA as EPI, its application as anti-TB drugs still needs further investigation.

\section{Additional file}

Additional file 1: Table S1. Differential expression of efflux pump genes under RIF, INH, VP+RIF and VP + INH stress in MDR M tuberculosis isolates. Table S2. Differential expression of efflux pump genes under RIF, $I N H, E M B, V P+R I F, V P+I N H$, and $V P+E M B$ stress in mono-resistant $M$ tuberculosis isolates. (XLS $84 \mathrm{~kb}$ )

\section{Abbreviations}

ABC: ATP-binding cassette; ADC: Albumin-dextrose-catalase; CAP: Capreomycin; EMB: Ethambutol; EPI: Efflux pump inhibitor; INH: Isoniazid; KAN: Kanamycin; LMM: Linear mixed model; MATE: Multidrug and toxic compound extrusion; MDR: Multi-drug resistant; MIC: Minimum inhibitory concentration; OFX: Ofloxacin; PACE: Proteobacterial antimicrobial compound efflux; RIF: Rifampicin; RND: Resistance-nodulation-division; SMR: Small multidrug resistance; STR: Streptomycin; VP: Verapamil; XDR: Extensively drug-resistant

\section{Acknowledgments}

We would like to thank all the personnel of Mycobacteriology and Pulmonary Research Department, Pasteur Institute of Iran, for their assistance in this project. We also appreciate the cooperation of all the colleagues at the Research Center Borstel, especially Stefan Niemann and Thomas A. Kohl, in performing the Next Generation Sequencing workflow.

\section{Funding}

This work was supported by a Ph.D. grant from Pasteur Institute of Iran and a grant (project no. 94009958) from Iran National Science Foundation (INSF). These funding bodies had no role in study design, data collection and analysis, decision to publish, or preparation of the manuscript.

\section{Availability of data and materials}

The datasets used and/or analyzed during the current study could become available through the corresponding author on reasonable request.

\section{Authors' contributions}

HG wrote the manuscript. FV supervised the project and revised the manuscript. FV, SDS, AF and FR designed the project. MY participated in analysis of data. $\mathrm{HG}$, MKK performed laboratory work. SK, MM and SP isolated the strains and contributed to laboratory work. All authors read and approved the final manuscript.

\section{Ethics approval and consent to participate}

Ethical reviews and informed consent approval were granted by the Ethical Committee of the Pasteur Institute of Iran.

\section{Consent for publication}

Not applicable.

\section{Competing interests}

The authors declare that they have no competing interests.

\section{Publisher's Note}

Springer Nature remains neutral with regard to jurisdictional claims in published maps and institutional affiliations.

\section{Author details}

${ }^{1}$ Department of Mycobacteriology and Pulmonary Research, Pasteur Institute of Iran, Tehran, Iran. ${ }^{2}$ Microbiology Research Center (MRC), Pasteur Institute of Iran, No. 358, 12th Farvardin Ave, Jomhoori St, Tehran 1316943551, Iran. ${ }^{3}$ Department of Epidemiology and Biostatistics, Tehran University of Medical Sciences, Tehran, Iran.

Received: 29 January 2019 Accepted: 29 March 2019

Published online: 02 May 2019

References

1. Raviglione MC, Uplekar MW. WHO's new stop TB strategy. Lancet. 2006; 367(9514):952-5.

2. Organization WHO. Global tuberculosis report 2017, vol. 2018. Genev: World Health Organization; 2017.

3. Raviglione M. XDR-TB: entering the post-antibiotic era? Int J Tuberc Lung Dis. 2006;10(11):1185-7.

4. Böttger $E$. The ins and outs of Mycobacterium tuberculosis drug susceptibility testing. Clin Microbiol Infect. 2011;17(8):1128-34.

5. Nikaido H. Preventing drug access to targets: cell surface permeability barriers and active efflux in bacteria. Semin Cell Dev Biol. 2001;12(3):215-23.

6. da Silva PEA, Machado D, Ramos D, Couto I, Von Groll A, Viveiros M. Efflux Pumps in Mycobacteria: Antimicrobial Resistance, Physiological Functions, and Role in Pathogenicity. In: Li XZ, Elkins C, Zgurskaya H. (eds) EffluxMediated Antimicrobial Resistance in Bacteria. Adis, Cham; 2016. p.527-59.

7. Gygli SM, Borrell S, Trauner A, Gagneux S. Antimicrobial resistance in Mycobacterium tuberculosis: mechanistic and evolutionary perspectives. FEMS Microbiol Rev. 2017:41(3):354-73.

8. Li X-Z, Nikaido H. Efflux-mediated drug resistance in bacteria. Drugs. 2009; 69(12):1555-623.

9. Narang A, Giri A, Gupta S, Garima K, Bose M, Varma-Basil M. Contribution of putative efflux pump genes to isoniazid resistance in clinical isolates of Mycobacterium tuberculosis. Int J Mycobacteriol. 2017;6(2):177.

10. Kanji A, Hasan R, Zhang Y, Shi W, Imtiaz K, lqbal K, et al. Increased expression of efflux pump genes in extensively drug-resistant isolates of Mycobacterium tuberculosis. Int J Mycobacteriol. 2016:5:S150.

11. Blanco P, Hernando-Amado S, Reales-Calderon J, Corona F, Lira F, AlcaldeRico M, et al. Bacterial multidrug efflux pumps: much more than antibiotic resistance determinants. Microorganisms. 2016:4(1):14.

12. Song $L$, Wu X. Development of efflux pump inhibitors in antituberculosis therapy. Int J Antimicrob Agents. 2016:47(6):421-9.

13. Du D, Wang-Kan X, Neuberger A, van Veen HW, Pos KM, Piddock LJV, et al. Multidrug efflux pumps: structure, function and regulation. Nat Rev Microbiol. 2018;16(9):523-39.

14. da Silva PEA, Von Groll A, Martin A, Palomino JC. Efflux as a mechanism for drug resistance in Mycobacterium tuberculosis. FEMS Immunol Med Microbiol. 2011;63(1):1-9.

15. Machado D, Couto I, Perdigão J, Rodrigues L, Portugal I, Baptista P, et al. Contribution of efflux to the emergence of isoniazid and multidrug resistance in Mycobacterium tuberculosis. PLoS One. 2012;7(4):e34538.

16. Viveiros M, Martins M, Rodrigues L, Machado D, Couto I, Ainsa J, et al. Inhibitors of mycobacterial efflux pumps as potential boosters for antitubercular drugs. Expert Rev Anti-Infect Ther. 2012;10(9):983-98.

17. Amaral L, Martins M, Viveiros M. Enhanced killing of intracellular multidrugresistant Mycobacterium tuberculosis by compounds that affect the activity of efflux pumps. J Antimicrob Chemother. 2007;59(6):1237-46.

18. Pule CM, Sampson SL, Warren RM, Black PA, van Helden PD, Victor TC, et al. Efflux pump inhibitors: targeting mycobacterial efflux systems to enhance TB therapy. J Antimicrob Chemother. 2015;71(1):17-26.

19. Rodrigues L, Machado D, Couto I, Amaral L, Viveiros M. Contribution of efflux activity to isoniazid resistance in the Mycobacterium tuberculosis complex. Infect Genet Evol. 2012;12(4):695-700.

20. Singh K, Kumar M, Pavadai E, Naran K, Warner DF, Ruminski PG, et al. Synthesis of new verapamil analogues and their evaluation in combination 
with rifampicin against Mycobacterium tuberculosis and molecular docking studies in the binding site of efflux protein Rv1258c. Bioorg Med Chem Lett. 2014;24(14):2985-90.

21. Vaziri F, Kohl TA, Ghajavand H, Kargarpour Kamakoli M, Merker M, Hadifar S, et al. Genetic Diversity of Multi- and Extensively Drug-Resistant Mycobacterium tuberculosis Isolates in the Capital of Iran, Revealed by Whole-Genome Sequencing. J Clin Microbiol. $2019 ; 57(1)$

22. Organization WHO. Updated interim critical concentrations for first-line and second-line DST (as of May 2012). Geneva: World Health Organization; 2012.

23. Leonard B, Coronel J, Siedner M, Grandjean L, Caviedes L, Navarro P, et al. Inter-and intra-assay reproducibility of microplate Alamar blue assay results for isoniazid, rifampicin, ethambutol, streptomycin, ciprofloxacin, and capreomycin drug susceptibility testing of Mycobacterium tuberculosis. J Clin Microbiol. 2008:46(10):3526-9.

24. Li G, Zhang J, Guo Q, Wei J, Jiang Y, Zhao X, et al. Study of efflux pump gene expression in rifampicin-monoresistant Mycobacterium tuberculosis clinical isolates. J Antibiot. 2015;68(7):431.

25. Livak KJ, Schmittgen TD. Analysis of relative gene expression data using realtime quantitative PCR and the 2- $\Delta \Delta C T$ method. Methods. 2001;25(4):402-8.

26. Louw $G$, Warren $R$, van Pittius NG, McEvoy C, Van Helden P, Victor T. A balancing act: efflux/influx in mycobacterial drug resistance. Antimicrob Agents Chemother. 2009:53(8):3181-9.

27. Shi R, Itagaki N, Sugawara I. Overview of anti-tuberculosis (TB) drugs and their resistance mechanisms. Mini Rev Med Chem. 2007:7(11):1177-85.

28. Srivastava S, Musuka S, Sherman C, Meek C, Leff R, Gumbo T. Effluxpump—derived multiple drug resistance to Ethambutol Monotherapy in Mycobacterium tuberculosis and the pharmacokinetics and pharmacodynamics of Ethambutol. J Infect Dis. 2010;201(8):1225-31.

29. Chen C, Gardete S, Jansen RS, Shetty A, Dick T, Rhee KY, et al. Verapamil Targets Membrane Energetics in Mycobacterium tuberculosis. Antimicrob Agents Chemother. 2018;62(5)

30. Li G, Zhang J, Guo Q, Jiang Y, Wei J, Zhao L-I, et al. Efflux pump gene expression in multidrug-resistant Mycobacterium tuberculosis clinical isolates. PLoS One. 2015;10(2):e0119013.

31. Putman M, van Veen HW, Konings WN. Molecular properties of bacterial multidrug transporters. Microbiol Mol Biol Rev. 2000;64(4):672-93.

32. Rodriguez $\mathrm{GM}$, Smith I. Identification of an $\mathrm{ABC}$ transporter required for iron acquisition and virulence in Mycobacterium tuberculosis. J Bacteriol. 2006; 188(2):424-30

33. Guilfoile $P G$, Hutchinson CR. A bacterial analog of the mdr gene of mammalian tumor cells is present in Streptomyces peucetius, the producer of daunorubicin and doxorubicin. Proc Natl Acad Sci. 1991 88(19):8553-7.

34. Malla S, Niraula NP, Liou K, Sohng JK. Self-resistance mechanism in Streptomyces peucetius: overexpression of $\operatorname{drr} A, \operatorname{drr} B$ and $\operatorname{drr} C$ for doxorubicin enhancement. Microbiol Res. 2010;165(4):259-67.

35. Gupta AK, Katoch VM, Chauhan DS, Sharma R, Singh M, Venkatesan K, et al. Microarray analysis of efflux pump genes in multidrug-resistant Mycobacterium tuberculosis during stress induced by common antituberculous drugs. Microb Drug Resist. 2010;16(1):21-8.

36. Choudhuri BS, Bhakta S, Barik R, Joyoti B, Kundu M, Chakrabarti P. Overexpression and functional characterization of an ABC (ATP-binding cassette) transporter encoded by the genes drrA and drrB of Mycobacterium tuberculosis. Biochem J. 2002:367(1):279-85.

37. Pang Y, Lu J, Wang Y, Song Y, Wang S, Zhao Y. Study of the rifampin monoresistance mechanism in Mycobacterium tuberculosis. Antimicrob Agents Chemother. 2013;57(2):893-900.

38. Hartkoorn RC, Uplekar S, Cole ST. Cross-resistance between clofazimine and bedaquiline through upregulation of MmpL5 in Mycobacterium tuberculosis. Antimicrob Agents Chemother. 2014; 58(5):2979-81.

39. Sandhu P, Akhter Y. The internal gene duplication and interrupted coding sequences in the MmpL genes of Mycobacterium tuberculosis: towards understanding the multidrug transport in an evolutionary perspective. Int J Med Microbiol. 2015;305(3):413-23.

40. Machado D, Coelho TS, Perdigão J, Pereira C, Couto I, Portugal I, et al. Interplay between mutations and efflux in drug resistant clinical isolates of Mycobacterium tuberculosis. Front Microbiol. 2017;8:711.

41. Oh TS, Kim YJ, Kang HY, Kim C-K, Cho SY, Lee HJ. RNA expression analysis of efflux pump genes in clinical isolates of multidrug-resistant and extensively drug-resistant Mycobacterium tuberculosis in South Korea. Infect Genet Evol. 2017:49:111-5.

42. Rodrigues L, Villellas C, Bailo R, Viveiros M, Aínsa JA. Role of the Mmr efflux pump in drug resistance in Mycobacterium tuberculosis. Antimicrob Agents Chemother. 2013:57(2):751-7.

\section{Ready to submit your research? Choose BMC and benefit from:}

- fast, convenient online submission

- thorough peer review by experienced researchers in your field

- rapid publication on acceptance

- support for research data, including large and complex data types

- gold Open Access which fosters wider collaboration and increased citations

- maximum visibility for your research: over $100 \mathrm{M}$ website views per year

At BMC, research is always in progress.

Learn more biomedcentral.com/submissions 